\title{
A dificuldade de morar. Exercícios de poder no fenômeno dos sem-abrigo'
}

João Aldeia ${ }^{2}$

Resumo: De modo dominante, os sem-abrigo são percebidos como indivíduos anormais e/ou anormativos que vivem na rua devido a esta insuficiência fundamental. Desta forma, considera-se que cada indivíduo sem-abrigo só poderá sair da rua se, sob a tutela de um profissional assistencialista, modificar quem e o que é. Essa relação tutelar apresenta-se como uma forma de dominação na qual os sem-abrigo são incentivados e/ou coagidos a aceitar a sua posição desqualificada. Usando como base empírica da reflexão o processo de cedência de moradas institucionais a sem-abrigo para que estes possam receber correspondência, o texto aborda diferentes exercícios e lógicas de poder pelas quais é produzida a submissão sociopolítica dos sem-abrigo.

Palavras-chave: Governamentalidade da vida na rua; Morada; Poder; Sem-abrigo.

\section{Inhabiting difficulties. Power exercises in homelessness.}

Abstract: The homeless are commonly perceived as individuals who live on the street due to their fundamental inadequacy. As such, it is generally considered that each

1 Este texto resulta da investigação de doutoramento em Sociologia que realizei na Faculdade de Economia da Universidade de Coimbra, com o acolhimento científico do Centro de Estudos Sociais da mesma universidade, financiada pela Fundação para a Ciência e a Tecnologia com a bolsa individual de doutoramento com a referência SFRH/BD/85867/2012. Agradeço a Ana Manso, Sílvia Portugal e Sónia Ferreira pela leitura do texto e comentários. Todos os problemas que permaneçam são da minha responsabilidade. Centro de Ecologia Funcional da Universidade de Coimbra - Coimbra - Portugal - alvesaldeia@gmail.com 
homeless individual can only leave the street if he changes who and what he is. To be able to do this, it is accepted that he has to be under the tutelage of a welfare professional. This tutelary relationship presents itself as a form of domination in which the homeless are encouraged and/or coerced to accept their disqualified position. Empirically anchored in the provision of institutional addresses to homeless individuals so that they can receive mail, this article reflects on different exercises and logics of power by which the sociopolitical submission of the homeless is produced.

Keywords: Address; Governmentality of life on the street; Homeless; Power.

\section{Introduç̃̃o}

O dispositivo de governo da vida na rua corresponde ao conjunto de instituições, atores, procedimentos, enunciados etc. que, de modo direto ou indireto, influenciam a forma do fenômeno dos sem-abrigo. Esse dispositivo tende a operar no registo da individualização patológica do fenômeno dos sem-abrigo: invisibilizando e/ou naturalizando as suas dimensões estruturais (e.g., o modo de organização dos mercados habitacional e de trabalho, a forma como os órgãos políticos oficiais se relacionam com os sujeitos), cada sujeito sem-abrigo é percebido como inerentemente anormal (doente e/ou deficiente mental) e/ ou anormativo (preguiçoso, mentiroso, aproveitador, debochado, toxicodependente, alcoólico). Face a isto, o objetivo estratégico desta rede de elementos é a normalização e normativização dos indivíduos e da população sem-abrigo.

Neste registo de ação, o dispositivo produz efeitos de realidade pela mobilização de diferentes procedimentos de poder, aqui conceptualizados a partir da herança de Foucault (1994; 2006; 2009; 2012a). Esses procedimentos visam tanto disciplinar cada indivíduo sem-abrigo, tornando-o dócil, quanto regular a população sem-abrigo. Essas orientações individualizantes e totalizantes são duas dimensões fundamentais da biopolítica moderna que, na conceptualização foucaultiana, apresenta-se como um exercício em prol da vida, como um poder de "fazer viver ou rejeitar para a morte" (Foucault, 1994; 2006) que procura não só preservar a vida como dar-lhe uma forma particular.

Contudo, no fenômeno dos sem-abrigo, a estratégia biopolítica nunca se apresenta como um estímulo indiscriminado da vida. Tanto quanto biopolítica, a lógica operativa do dispositivo permanece soberana, exercendo-se como um poder de "matar ou deixar viver" (Foucault, 1994; 2006; 2012a). Isso constrange as possibilidades de vida dos sem-abrigo, tornando formas variadas de morte sociopolítica onipresentes na estratégia do dispositivo de governo da vida na 
rua. A vida que o dispositivo procura preservar é a vida biológica de cada indivíduo sem-abrigo e não a sua vida politicamente qualificada.

Este modus operandi do poder expõe a vida dos sem-abrigo a ações arbitrárias de diversos atores domiciliados que, com boa ou má vontade, condicionam as possibilidades de vida dos primeiros. Deste modo, em termos rigorosos, a estratégia de ação do dispositivo de governo da vida na rua não é biopolítica tout court. Antes, ela assume a forma de uma bio-tanato-política que faz os sem-abrigo sobreviver sem nunca lhes permitir afastarem-se significativamente do limiar entre a vida e a morte.

Esta amálgama de mecanismos de poder em operação no fenômeno dos sem-abrigo resulta numa lógica de intervenção condicional na qual é fornecida uma assistência minimalista aos sem-abrigo em troca da sua participação numa relação tutelar (formalizada ou não na figura do gestor de caso). No seio desta relação, cada sem-abrigo é analisado na sua anormalidade e/ou anormatividade, sendo incentivado a realizar um processo de ressubjetivação. De forma idealizada, por este processo, o sujeito deixaria de ser anormal e/ou anormativo, logo, adquiriria condições de possibilidade íntimas para deixar de ser sem-abrigo. Contudo, na prática, a relação tutelar de facto existente obstaculiza a própria possibilidade desse processo de transformação de si poder ter o sucesso pretendido pelo dispositivo de governo da vida na rua - sobretudo, dado que essa relação se desenvolve no contexto da ausência de ação no sentido de qualquer mudança estrutural. Assim, na maioria das situações, a relação tutelar torna-se numa forma de dominação no seio da qual se visa efetivar de facto uma transformação de cada sujeito sem-abrigo, mas no sentido de este se tornar submisso. $O$ resultado dessa forma da operação das tecnologias de poder mobilizadas pelo dispositivo é a constante negação de direitos - no limite, é a negação do arendtiano "direito a ter direitos" (Arendt, 2010: 353-401) - aos sem-abrigo e o estímulo da sua aceitação do tipo particular de vida desqualificada que lhes é imputada.

Uma das tecnologias (i.e., dos procedimentos de poder, mais ou menos formalizados, que produzem efeitos de realidade) mobilizadas pelo dispositivo de governo da vida na rua que mais explicitamente espelha a amálgama bio-tanato-política é a cedência de moradas. Esta consiste na permissão concedida por profissionais assistencialistas a indivíduos sem-abrigo que pernoitam na rua em sentido literal ${ }^{3}$ para que estes últimos usem a morada administrativa da ins-

3 Ou em espaços não previstos para pernoita humana, tais como edifícios abandonados, muitas vezes em estados de conservação arquitetônica muitíssimo degradado, colocando em causa a integridade física de quem neles dorme. 
tituição para a qual trabalham os primeiros, de modo a poderem receber correspondência. Na operação dessa tecnologia, são nítidos vários dos procedimentos e lógicas de poder característicos do governo da vida na rua.

Neste texto, como base empírica para pensar a operação do dispositivo de governo da vida na rua, mobilizo o trabalho de campo que realizei no âmbito de uma pesquisa de doutoramento. Em particular, durante alguns meses, observei reuniões interinstitucionais periódicas nas quais estavam presentes profissionais assistencialistas (sobretudo, assistentes sociais e psicólogos) e profissionais da área da psiquiatria em representação de diversas instituições públicas e terceiro setor que intervêm quotidianamente no fenômeno dos sem-abrigo.

Este trabalho não pode deixar de ser localizado no espaço e no tempo, não pretendendo valer por quaisquer critérios de representatividade. Antes, a investigação assume-se como heuristicamente válida enquanto exemplar. Tendo a observação das reuniões sido realizada numa cidade portuguesa de média dimensão, em 2013 e 2014 $4^{4}$, necessariamente, haverá questões que são particulares a esta realidade e que poderão não estar presentes noutros espaços-tempo, ou não o estar com a mesma importância relativa. Não obstante, o registo de observação reflexiva mobilizado permite abrir uma porta para a compreensão não só do contexto particular estudado mas do próprio dispositivo de governo da vida na rua. Ainda que este último não seja igual em toda a parte, ele apresenta fortes isomorfismos à escala do modelo societal moderno ocidental que estão para além dos campos empíricos concretos das investigações.

\section{Vida na rua}

O fenômeno dos sem-abrigo é uma forma de vida na rua. Esta expressão indica que há uma forma de vida específica estrutural e ontologicamente associada aos sem-abrigo, bem como que a rua é um espaço social particular. Interpretando a rua a partir da experiência de dominação dos sem-abrigo, ela apresenta-se como um espaço de exceção permanente, como uma "zona de indistinção" (Agamben, 1998; 2010) na qual a normatividade (escrita como lei ou regulamento e/ou transmitida culturalmente na sucessão das gerações) dominante que regula as vidas dos sujeitos domiciliados das classes médias e elites é suspensa e, podendo reter validade de jure, não é de facto aplicável na orientação das interações em que os sem-abrigo estão presentes, nomeadamente, daquelas em que estes se relacionam com não-sem-abrigo. Na rua, esta normatividade é

4 O trabalho de campo total, realizado na mesma cidade mas recorrendo a outros processos de produção de informação, decorreu entre 2010 e 2014. 
substituída por exercícios arbitrários de poder que condicionam as possibilidades de vida dos sem-abrigo ao permitirem ou impedirem que estes acedam a recursos e sejam tratados com respeito (Arnold, 2004; Feldman, 2006).

Em termos exatos, a normatividade dominante não tem, forçosamente, de estar ausente na regulação das interações em que os sem-abrigo estão envolvidos. Ela pode de facto, a espaços, servir para as orientar. Porém, aplicando-se ou não se aplicando, a sua efetivação ou não efetivação está para além da capacidade de influência dos próprios sem-abrigo. É outrem que não eles que decide, a cada momento específico, se uma normatividade de jure válida é mobilizável para regular uma interação ou se, pelo contrário, esta última constitui uma situação de exceção e, logo, deve ser orientada segundo a vontade do decisor. Deste modo, como zona de indistinção, a rua caracteriza-se pela mobilização de um "direito de matar ou deixar viver" (Foucault, 1994; 2006) pelos sujeitos que, temporariamente e com intensidades diferentes consoante a sua posição hierárquica e heterárquica, comportam-se como soberanos face aos sem-abrigo.

Numa conceptualização schmittiana, "o soberano é aquele que decide sobre a exceção" (Schmitt, 2005: 5), ${ }^{5}$ indicando que este sujeito se encontra na posição de, a cada instante, decidir se uma situação constitui ou não uma exceção $e$, em simultâneo, caso a considere excecional, decidir que conjunto de procedimentos casuísticos mobilizar para orientar a interação (Strong, 2005: xii). O modelo societal ocidental contemporâneo coloca limites a esta posição, impedindo - pelo menos, à esmagadora maioria dos sujeitos e na esmagadora maioria das situações - que seja dada morte biológica aos sem-abrigo. Porém, face aos sem-abrigo todos os sujeitos domiciliados das classes médias e elites podem comportar-se como soberanos, pois, de forma arbitrária, as suas ações podem diminuir significativamente as possibilidades de vida de quem vive na rua. Normalizando-se o caráter excecional dos exercícios de poder na rua ${ }^{6}$, a cada instante, o tratamento dos sem-abrigo fica dependente não de uma normatividade estável, mas, pelo contrário, da boa ou má vontade de cada não-sem-abrigo que, naquela ocasião, assume o exercício da soberania.

Existindo na exceção permanente, os sem-abrigo tornam-se dependentes do arbítrio soberano com que outrem os pode bem ou maltratar, o que os reduz de facto a uma forma de vida nua, a uma vida constantemente exposta à possibilidade aleatória de lhe ser dada morte (Agamben, 1998) - no caso, sobretudo, morte política. Aprisionados no espaço social da rua, os sem-abrigo são 
politicamente abandonados ao ser-lhes vedada uma qualificação como bios, a vida política que os gregos clássicos associavam à polis, e ao serem circunscritos a uma existência como zoe, como pura vida biológica, "o simples facto de viver" (Agamben, 1998: 11), associada na Antiguidade helênica ao espaço do oikos (Agamben, 1998; Arendt, 2001).

Classicamente, essa vida biológica, tendo como objetivo exclusivo a reprodução individual e da espécie, era desqualificada face à bios. Esta última era a vida naquilo que nela se reporta à produção de algo mais do que o estritamente necessário à sua reprodução, característica de todos os cidadãos livres. Por seu lado, a zoe surgia como forma de vida que era reservada a todos os que não eram cidadãos - escravos, mulheres, crianças, bárbaros. Estes últimos sujeitos, tendo as suas vidas consumidas com a reprodução biológica, atividade elementar que partilhavam com os animais não humanos, eram percebidos como não inteiramente humanos devido à sua desqualificação política (Agamben, 1998; Arendt, 2001: 52 et passim).

Com o início da modernidade ocidental, a vida biológica penetrou firmemente no espaço político que, anteriormente, era o domínio da bios (Agamben, 1998; Arendt, 2001; Esposito, 2010; 2011; Foucault, 1980a; 1994; 2006). Neste movimento de politização do biológico pela sua transformação em assunto público, a zoe tornou-se objeto de ação política e, deste modo, deixou de ser exatamente aquilo que era para os gregos clássicos. Ela se transformou em vida nua precisamente ao tornar-se numa forma de vida biológica que, porém, existe no espaço da bios e, assim, passa a estar dependente do arbítrio com que outrem pode condicionar as suas possibilidades de existência, mantendo-as, aumentando-as, diminuindo-as ou eliminando-as (Agamben, 1998).

Ao serem abandonados na rua como exceção permanente, é esta vida nua, e não meramente a zoe, que caracteriza os sem-abrigo. Estes sujeitos não são, pura e simplesmente, deixados existir. A sua manutenção vital não é deixada ao sabor de um acaso natural para lá de qualquer possibilidade ou interesse de intervenção política. Ela é deixada ao sabor do acaso, mas do acaso politicamente intervencionado. A vida dos sem-abrigo é exposta em toda a sua nudez na exata medida em que é tornada assunto público. Ela está despida face à aleatoriedade do exercício do poder. É esta forma de acaso que a condiciona, proveniente da prerrogativa soberana pela qual as suas possibilidades de manutenção, desenvolvimento ou eliminação são decididas, com quase total liberdade e impunidade, por outrem que não o próprio sujeito que vive na rua. 


\section{0 dispositivo de governo da vida na rua}

O dispositivo de governo da vida na rua, conceptualizado neste texto a partir de uma herança intelectual foucaultiana (Foucault, 198ob; 1994; 2009; 2010; 2012a), corresponde à rede de elementos - instituições, atores, procedimentos, enunciados, objetos etc. - que, de modo direto ou indireto, contribuem para dar uma forma específica ao fenômeno dos sem-abrigo num espaço-tempo concreto. Esse dispositivo é composto por dois subdispositivos. Por um lado, ele tem uma parte oficial, composta por aqueles elementos que são formalmente incumbidos da intervenção na vida na rua e sobre os sem-abrigo (Instituto da Segurança Social, Instituições Particulares de Solidariedade Social, decisores de políticas públicas da pobreza, instituições psiquiátricas que lidam frequentemente com sem-abrigo, órgãos diversos do Estado central e local). Por outro lado, o dispositivo tem uma parte não oficial, correspondente àqueles elementos que não são formalmente legitimados para produzir efeitos de realidade sobre o fenômeno dos sem-abrigo, mas cuja ação quotidiana, contudo, produz tais efeitos, condicionando as possibilidades de vida de quem vive na rua (associações de moradores e comerciantes cujos espaços residenciais e comerciais se encontram em áreas de circulação habitual de populações sem-abrigo, polícia, decisores econômicos locais, nacionais e transnacionais cujas ações influenciam a vida da esmagadora maioria dos sujeitos numa localidade, país ou no globo, órgãos de comunicação social, partes da Academia que trabalham sobre o tema). Se o fenômeno dos sem-abrigo é, em si mesmo, o conjunto de elementos heterogêneos agonisticamente articulados que têm alguma relação mais ou menos direta com a vida na rua, então, ele é o dispositivo de governo da vida na rua. Necessariamente, na medida em que os sem-abrigo não são meros recetáculos de exercícios de poder ou entidades que simplesmente reagem ao que lhes é feito, esses sujeitos são tanto parte do dispositivo quanto os outros atores envolvidos.

Os dispositivos implicam a circulação simultânea de fluxos de saber e poder que estão sempre inextricavelmente relacionados. Por sua vez, estas relações de saber-poder produzem sempre subjetivações específicas, criam tipos de sujeito (Agamben, 2009; Binkley, 2011; Deleuze, 1992; Foucault, 1980b; 1994; 2009; 2010; 2012a; 2012b). Nesta medida, ao mesmo tempo e com igual peso relativo, os dispositivos revelam-se sempre produtivos e destrutivos, criadores e constrangedores. Em particular, geram condições de possibilidade de certos modos particulares de enunciação, ação e subjetivação, fazendo isto, necessariamente, 
à custa do impedimento ativo de outras formas de dizer e agir e de outros processos de constituição de (outros tipos de) sujeitos.

A agregação heterogênea e agonística de elementos que é o dispositivo gera uma intencionalidade global, estratégica, que não corresponde nunca de modo exato às intenções individuais de cada um dos seus elementos. Essa estratégia de ação é, acima de qualquer outra coisa, não-subjetiva (Deleuze, 1992; Elias, 1997; 2004; 2005; 2006; Foucault, 1980b; 1994; 2009; 2010; Law, 1991; Raffnsøe; Gudmand-Høyer; Thaning, 2014). À semelhança da mudança social numa conceptualização eliasiana, a estratégia de um dispositivo vai "crescendo por planos, mas de forma não planeada" (Elias, 2004: 85). As racionalidades, intenções e ações individuais associam-se umas com as outras progressivamente, numa lógica conflitual, levando a que o resultado de cada momento de confronto não equivalha nunca ao que fora planeado por qualquer um dos elementos individuais do dispositivo. A estratégia holística que daqui resulta tem uma inércia própria, condicionando as ações dos elementos individuais do dispositivo - ainda que essa estratégia apenas possa existir a partir da associação de todas as ações individuais que a compõem.

Essa intencionalidade estratégica do dispositivo, de forma incontornável, torna-o num fenômeno de "governo". Até ao Século XVII, o termo "governo" não tinha o significado contemporâneo de executivo governamental formal de um Estado-nação. Antes, esse termo remetia para o conjunto "de mecanismos e de procedimentos destinados a conduzir os homens, a dirigir a conduta dos homens, a conduzir a conduta dos homens" (Foucault, 2012b: 14). Neste sentido, o exercício de governo é aquele agregado de ações humanas que tem como objetivo a condução de conjuntos de elementos, nomeadamente, mas não só, humanos, procurando dispô-los de uma certa forma para atingir objetivos específicos. Governar é exercer uma certa "condução de condutas" que respeita os princípios tácitos e explícitos de uma dada "governamentalidade", de uma certa "arte de governo", de uma certa "racionalidade de governo" (Foucault, 1983; 2009; 2010; 2012b). Governar é procurar que um fenômeno espacio-temporalmente concreto atinja uma forma pretendida, de modo subjetivo ou não subjetivo, implicando que os seus elementos, na sua agregação como população e na sua individualidade, precisem de ser guiados até que cada um deles e as relações entre eles circulem de um modo desejável. No esquema de qualquer governamentalidade, a produção de tais efeitos de realidade é conseguida através da ação de dispositivos.

A estratégia governamental do dispositivo de governo da vida na rua não visa eliminar o fenômeno dos sem-abrigo. Antes, este dispositivo pretende gerir, 
conduzir, os indivíduos e a população sem-abrigo até que eles adquiram uma certa forma. De modo geral, a ação governamental na vida na rua apresenta-se como uma individualização patológica que tem duas orientações fundamentais.

Por um lado, a individualização patológica opera num registo de normativização dos sem-abrigo, procurando que eles se transformem em sujeitos submissos à normatividade dominante num dado espaço-tempo através de ações punitivas. Esse modus operandi tem uma longa história no mundo ocidental, acompanhando o fenômeno dos sem-abrigo desde o seu surgimento na forma atual, nas décadas de 1970 e 1980 (Hopper, 2003; Gowan, 2010). Mas, antes disto, essa racionalidade de governo é predominante na conceptualização da e ação sobre a pobreza desde a Idade Média europeia, oscilando historicamente o tratamento dos pobres entre a "piedade" e a "forca" (Geremek, 2010). Nesse registo, os sem-abrigo são sujeitos preguiçosos, desonestos, debochados, alcoólicos, toxicodependentes, aproveitadores, que recusam comportar-se de acordo com a normatividade dominante e preferem sobreviver à custa da generosidade coletiva e individual alheia.

Por outro lado, a individualização patológica desenvolve-se de acordo com um registo medicalizante que percebe os sem-abrigo e age sobre eles como sujeitos inerentemente anormais, neuro-psiquiatricamente errados. Essa racionalidade de governo da vida na rua emergiu no final da década de 1980 e é hoje em dia dominante (Gowan, 2010; Hopper, 2003; Lovell, 1992; Lyon-Callo, 2008; Mathieu, 1993; Wasserman; Clair, 2010). A medicalização é um processo de extensão de uma grelha conceptual de origem médica à totalidade ou quase totalidade do campo social de um fenômeno, previamente interpretado de outra forma, passando os seus atores a mobilizar discursos, definições, enfim, toda uma semântica médica para abordá-lo (Conrad, 1992; 2007; Conrad; Schneider, 1992). No caso da vida na rua, essa racionalidade consiste na representação ubíqua dos sem-abrigo como doentes e/ou deficientes mentais ${ }^{7}$ que importa normalizar através de procedimentos e relações derivadas do dispositivo médico (em particular, psiquiátrico).

Privilegiando uma ou outra destas orientações da individualização patológica, ou mesclando-as, o dispositivo de governo da vida na rua fragmenta o fenômeno dos sem-abrigo numa multiplicidade de entidades ontologicamente inferiores. Em geral, a medicalização tende a se articular com a normativização,

7 Mas também como alcoólicos e toxicodependentes, pois essas duas questões são em si mesmas recodificadas num campo medicalizado como problemas neuro-psiquiátricos. 
levando a que os sem-abrigo sejam, em simultâneo, doentes $e$ perversos, necessitados de tratamento $e$ de punição. ${ }^{8}$

Essa intencionalidade estratégica se efetiva quer como exercício individualizado e individualizante, incidindo sobre os corpos individuais que vivem na rua, quer como exercício totalizante, visando regular a população sem-abrigo que existe num dado espaço-tempo. Apesar da individualização patológica privilegiar intervenções dirigidas a cada sujeito sem-abrigo isolado, as medidas de regulação populacional não estão ausentes - ainda que, muitas vezes, sejam consequências não reflexivamente planeadas do conjunto das ações individuais levadas a cabo pelos agentes do dispositivo de governo da vida na rua.

Numa matriz foucaultiana, essas duas lógicas da circulação do poder são indissociáveis (Foucault, 1994; 2006; 2009). Ambas são dimensões fundamentais da biopolítica moderna que emerge, do Século XVII em diante, já não como expressão do "direito de matar ou deixar viver", mas, pelo contrário, de um poder de "fazer viver ou rejeitar para a morte" (Foucault, 1994; 2006; 2009). Portanto, na modernidade ocidental, o poder deixa de se efetivar de modo privilegiado pelo lado da morte e se transforma numa intervenção continuada sobre a vida, "sobre a maneira de viver e sobre o "como» da vida" (Foucault, 2006: 264), o que, necessariamente, relega a morte para o seu limite, torna-a no ponto em que 0 poder deixa de se poder exercer.

$\mathrm{Na}$ biopolítica moderna, os exercícios individuais e individualizantes sobre os corpos individuais obedecem a uma lógica disciplinar de controlo total assente em diversas tecnologias: a vigilância ubíqua; o constrangimento espacial (e.g., encarceramento); o exame exaustivo e contínuo das ações e pensamentos dos sujeitos; a definição apriorística das atividades a realizar e das temporalidades em que estas devem ser executadas; e a punição generalizada e detalhada de todas as infrações à conduta prescrita. O objetivo central desta lógica de "vigiar e punir" (Foucault, 2012a) é intervir sobre o íntimo de cada indivíduo disciplinado, transformando-o num sujeito dócil (que não coloca em questão a forma da organização societal em que existe, que o prejudica) e útil (passível de ser utilizado pelo sistema produtivo capitalista).

No que toca ao nível totalizante, a biopolítica moderna apresenta-se como um exercício de regulação populacional (Foucault, 1980a; 1994; 2006; 2009). Na modernidade ocidental, os atos de governo passam a ter como objetivo a

8 Esta associação com a normativização não é uma idiossincrasia da medicalização da vida na rua. Antes, ela é uma característica constitutiva da própria medicalização, que, desde a sua gênese moderna, no Século XVIII, revela uma tendência simultaneamente normalizante e normativizante (Foucault, 1978; 1999; 2012a). 
preservação e o desenvolvimento vital da população existente num dado espaço-tempo. A estatística e a demografia tornam-se em tecnologias centrais desta regulação, permitindo identificar regularidades populacionais em torno de normas científicas, bem como desvios face à normalidade (i.e., situações em que uma população tem um comportamento atípico face a uma dada variável). Graças a isto, torna-se possível intervir tecnicamente sobre as condições de vida de uma população, corrigindo (i.e., normalizando) as condutas desta última que a afetam de modo negativo.

Apesar da governamentalidade da vida na rua revelar inegáveis orientações disciplinares e reguladoras, a estratégia biopolítica de governo deste fenômeno nunca se apresenta como um estímulo indiscriminado da vida dos sem-abrigo. Reduzindo os (indivíduos e a população) sem-abrigo a uma vida nua permanentemente exposta ao arbítrio com que sujeitos não-sem-abrigo condicionam as suas possibilidades de existência, a intencionalidade estratégica do dispositivo de governo da vida na rua é incontornavelmente bio-tanato-política. Tanto quanto uma forma de exercer poder sobre a vida, ela é um modo de exercer poder através da morte. A ação desse dispositivo é produtiva e destrutiva ao mesmo tempo, geradora e constrangedora com o mesmo peso relativo. $\mathrm{O}$ governo da vida na rua estimula ativamente a manutenção da vida biológica dos sem-abrigo. Mas esse campo de possibilidades de ação, discurso e subjetivação é feito existir à custa da anulação de quaisquer outros campos de possibilidades de ser alternativos, nomeadamente da esfera de ação na qual a bios poderia desenvolver-se. Desse modo, a governamentalidade da vida na rua não visa pura e simplesmente matar, ainda que tenha o efeito de reduzir a vida, nem fomentar de modo indiscriminado a vida, ainda que tenha o efeito de fazer viver. Antes, a estratégia global do dispositivo de governo da vida na rua apresenta-se como uma bio-tanato-política que faz os sem-abrigo sobreviver sem nunca lhes permitir afastarem-se de modo significativo desse limiar entre a vida e a morte. ${ }^{9}$

\section{A cedência institucional de moradas a quem não tem habitação}

Nas discussões entre profissionais das instituições envolvidas na intervenção assistencialista na vida na rua (sobretudo, mas não só, assistentes sociais e psicólogos), as questões práticas do quotidiano apresentam uma enorme

9 Esta conceptualização de uma bio-tanato-política que faz sobreviver no governo da vida na rua é derivada das reflexões de Esposito (2010, 2011) sobre o funcionamento do mecanismo imunitário na modernidade ocidental. O desenvolvimento do quadro conceptual deste autor está para além deste texto, mas impõe-se creditá-lo. 
relevância. Uma das questões fundamentais para diversos desses atores, recorrentemente abordada nas reuniões interinstitucionais que observei durante 0 trabalho de campo realizado, é o processo pelo qual cada instituição assistencialista atribui moradas aos sem-abrigo que pernoitam na rua em sentido literal (espaços públicos não previstos para a habitação, casas abandonadas etc.) para que estes sujeitos possam receber correspondência.

Não tendo casa, esses sem-abrigo não têm também uma localização administrativa onde possam ser contactados. Isso dificulta a sua localização, desde logo, pelos profissionais de diversas instituições quando estes desejam contactá-los. Essa dificuldade de contacto devido à ausência de morada pode ter consequências negativas consideráveis sobre as vidas dos sem-abrigo, tais como o agravamento de problemas judiciais ou a suspensão de uma prestação pública da pobreza, diminuindo significativamente as possibilidades de vida de quem vive na rua em sentido literal.

A cedência de moradas institucionais para que os sem-abrigo que pernoitam na rua em sentido literal possam receber correspondência é uma tecnologia de poder particularmente interessante para compreender a governamentalidade da vida na rua. Nesta tecnologia é notória a articulação de diversos mecanismos de poder e é identificável o caráter agonístico das práticas interligadas de diversos profissionais e instituições da parte oficial do dispositivo de governo da vida na rua. Por um lado, há instituições que cedem as suas moradas após um primeiro contato com um sujeito que se apresente como de tal necessitado aos olhos de um profissional assistencialista concreto. Por outro lado, há instituições que apenas cedem as suas moradas a sujeitos que aceitem ser acompanhados por um gestor de caso na instituição. A localização num ou noutro desses casos depende da normatividade oficial e informal de cada instituição concreta, bem como do arbítrio de cada profissional assistencialista que contata com um sem-abrigo necessitado de um local onde possa receber correspondência - sendo que este arbítrio é limitado pela normatividade institucional, mas esta, em si mesma, tem uma dose de aleatoriedade.

A prática de fazer a cedência de moradas institucionais depender da aceitação de um acompanhamento por um profissional assistencialista torna inegável que esta morada é usada como contrapartida num processo assistencialista condicional. Esse acompanhamento expressa-se como relação tutelar na qual se procura desenvolver aquilo que diversos profissionais assistencialistas designam como a "motivação para a mudança" do sem-abrigo tutelado. Pressupondo que este sujeito é sem-abrigo devido a uma insuficiência ontológica fundamental, que ele é inerentemente anormal e/ou anormativo, a possível solução 
conceptualizada e apresentada pelo dispositivo de governo da vida na rua é a ressubjetivação do sujeito sem-abrigo. Se ele é sem-abrigo por ser quem e o que é, só poderá deixar de ser sem-abrigo transformando-se. Num campo de práticas no qual os apoios prestados a quem vive na rua não são de facto direitos destes sujeitos derivados da sua mera necessidade, os fluxos assistencialistas que lhe são dirigidos são apresentados num registo de quid pro quo. Na medida em que a falta de recursos materiais é uma característica basilar da vida na rua, a única forma dos sem-abrigo pagarem esses apoios é darem-se a si mesmos, aceitando inserir-se nessa relação tutelar na qual trabalharão sobre si próprios para se ressubjetivarem.

Essa operação da tecnologia de cedência de moradas reduz de facto as possibilidades de vida dos sujeitos sem-abrigo no exato processo pelo qual se procura que esses se transformem. Assim é porque ela torna esta ressubjetivação dependente da aceitação de uma posição subordinada na relação tutelar na qual o seu bom ou mau tratamento, o acesso ou negação de recursos, o respeito ou desrespeito que lhe é dado, se encontra fora da sua capacidade de controlo e passam inteiramente para as mãos da parte superordinada que tutela. E, desde logo, num nível anterior, essa forma de operação da cedência de moradas sustenta a invisibilização da posição estrutural dos sem-abrigo, substituindo a observação das dinâmicas econômicas, políticas e sociais que dirigem os sujeitos para a vida na rua por uma interpretação individual voluntarista e patológica. Nesta medida, de base, a operação da cedência de moradas é inerentemente violenta, sustentando e sustentando-se na governamentalidade da vida na rua que, de modo ubíquo, diz a cada sem-abrigo que ele é um sujeito fundamentalmente errado, que as suas diminutas possibilidades de vida se devem a esta sua insuficiência ontológica e que, deste modo, a única forma dessas possibilidades de vida aumentarem (mesmo que apenas residualmente) é a modificação essencial de si mesmo.

Contudo, sendo a cedência de moradas um procedimento de poder, ela revela-se, em simultâneo, constrangedora e produtiva. Um dos seus objetivos é ultrapassar os bloqueios institucionais respeitantes à receção de correspondência (nomeadamente, correspondência oficial com Instituto da Segurança Social), logo, é facilitar o quotidiano da vida dos sem-abrigo e da atividade profissional assistencialista. Mas, ao mesmo tempo, a cedência de moradas é uma tecnologia estrategicamente indissociável do trabalho sobre si, tendo uma forte dimensão normativizante e normalizante. $\mathrm{O}$ fato dos sem-abrigo precisarem de uma morada oficial para poderem ter uma relação com várias das instituições do dispositivo de governo da vida na rua (com algumas Instituições Particulares 
de Solidariedade Social e, em particular, com o Instituto da Segurança Social) tem, inegavelmente, um propósito regulador biopolítico na medida em que é um processo que visa introduzir os sujeitos administrativamente na parte formalmente assistencialista do dispositivo. Tal mecanismo permite saber como contatar oficialmente os sujeitos, supondo que estes são inseridos numa relação assistencialista tutelar de trabalho sobre si. Portanto, a cedência de moradas institucionais para receção de correspondência apresenta-se de modo inegável como um meio de exercício de um biopoder simultaneamente dirigido à população sem-abrigo (a ser administrativamente localizada, a ser controlada) e a cada corpo individual que vive na rua (a ser introduzido como unidade numa base de dados, a ser alterado na sua essência). Mas todo o processo revela igualmente uma articulação fundamental com uma soberania necessariamente arbitrária na medida em que cada decisão casuística sobre a cedência ou não cedência desta morada é realizada por um profissional assistencialista no momento da sua interação com um sujeito sem-abrigo concreto, e logo, a partir da representação ontológica que faz desse sujeito - ele mente ou não mente, ele precisa ou não precisa, ele pode ou não ser ressubjetivado etc.

Há claras irracionalidades em todo este processo. Um jogo de ping-pong administrativo leva a que a morada oficial dos sujeitos possa mudar com frequência, dificultando o conhecimento exato do local onde estes podem ser contatados a cada momento. Ao ser acompanhado por um gestor de caso de uma instituição assistencialista, um sujeito que pernoite literalmente na rua tenderá a ter como morada oficial esta instituição. Caso ele passe a pernoitar num centro de acolhimento por um período de tempo limitado, a sua morada poderá ser alterada, passando para esta última instituição. Caso ele saia do centro de acolhimento, terá de alterar novamente a sua morada oficial, provavelmente para uma outra instituição do dispositivo. Tudo isso leva a que alguns sem-abrigo, não tendo casa, encontrem-se na estranha situação de mudarem de morada mais vezes do que muitos sujeitos domiciliados.

Os custos e atrasos de circulação da informação por diversos pontos do dispositivo, mesmo considerando apenas a sua parte oficialmente assistencialista, levam a que a informação que uma instituição tem sobre a morada para onde pode enviar correspondência a um sujeito concreto esteja, muitas vezes, desatualizada. Isso é particularmente problemático na relação com o Instituto da Segurança Social dado que tais moradas oficiais cedidas são, muitas vezes, a única forma que os sujeitos que pernoitam literalmente na rua têm de poder receber prestações públicas da pobreza, em particular, mas não só, o Rendimento Social 
de Inserção. ${ }^{10,11}$ As consequências negativas derivadas da falta de recebimento de correspondência proveniente desta instituição são significativas, sobretudo, pois todo este processo decorre num contexto de crescentes constrangimentos associados à receção desta prestação pública, regularmente formalizados pela assinatura de um contrato individual de reinserção (obrigatoriedade de realização de atividades específicas, de comparecer quando é convocado por profissionais assistencialistas, de apresentação de documentação comprovativa etc). Toda a comunicação escrita enviada pelo Instituto da Segurança Social para um sem-abrigo é dirigida para a morada oficial que o primeiro tem para o segundo, que poderá estar desatualizada ou ser uma morada com a qual o sujeito tem um contato menos frequente no momento (e.g., casos em que os sujeitos saíram de um centro de acolhimento e continuam temporariamente a receber lá a sua correspondência). Essa situação de desfasamento leva alguns sujeitos beneficiários a entrem em incumprimento formal do que foi estabelecido no âmbito dos contratos individuais de reinserção que assinaram, simplesmente, por desconhecimento de uma obrigação específica (e.g., comparecer a uma reunião ou entregar um documento) cuja notificação não receberam atempadamente. Por vezes, tais ocorrências resultam na suspensão ou fim do recebimento da prestação pública em causa por fatores incontroláveis pelos beneficiários.

Mas não só nesta relação institucional específica surgem problemas. Em particular, a correspondência enviada para estas moradas oficiais por instituições do sistema judicial leva a que, por vezes, pequenas questões jurídicas facilmente solucionáveis no seu início apenas cheguem ao conhecimento dos sem-abrigo depois

10 O Rendimento Social de Inserção foi instituído em Portugal em 2003, substituindo o Rendimento Mínimo Garantido, que vigorou desde 1996. Oficialmente, trata-se de uma prestação pública que procura garantir um rendimento mensal a sujeitos que não possuem outros rendimentos, visando combater situações de pobreza, mediante a assinatura de um contrato de inserção individual. Em 2015, tinha um valor máximo de $178.15 €$ mensais, o que correspondia a cerca de $35.3 \%$ do salário mínimo nacional $(505 €)$.

11 Para funcionarem de modo minimamente adequado, as políticas públicas têm de contemplar a heterogeneidade de situações dos seus recipientes potenciais e factuais. Ora, isto não se verifica na atribuição do Rendimento Social de Inserção a quem vive na rua. Tornar obrigatória uma morada para requerer esta prestação pública leva a que esta medida seja desajustada para a situação de maior pobreza que as sociedades ocidentais conhecem. Para mais, ainda que de forma não subjetivamente intencional, é insultuoso para um sem-abrigo ser colocado numa situação em que, para poder ser assistido com um reduzidíssimo rendimento mensal, tenha de ter uma morada - dado que esta é, em grande medida, a forma oficial do que lhe falta na praxis. Deste modo, apenas pervertendo o próprio sistema público é possível torná-lo minimamente operacional, levando a que partes do dispositivo tenham de criar moradas, em rigor, virtuais (pela sua não correspondência a uma habitação) para sujeitos cujo problema é a falta de habitação para que estes possam aceder a uma prestação pública que, nos enunciados oficiais do próprio Instituto da Segurança Social, deve ser por cada sem-abrigo aplicada para conseguir habitação. Aqui como noutros pontos, a estratégia de governo da vida na rua é feita de tensões permanentes. 
de ser ultrapassado o prazo legal previsto para a resolução da questão. Deste modo, quando estes sujeitos tomam conhecimento dessas questões judiciais, elas se revelam bastante mais problemáticas do que eram aquando do envio da correspondência, gerando multas, coimas ou mesmo penas de encarceramento prisional.

O governo da vida na rua revela claramente a sua dimensão coerciva quando a cedência de moradas institucionais é tornada dependente da aceitação dos sem-abrigo realizarem um trabalho sobre si sob a tutela de um gestor de caso da instituição que cede a morada. O poder exercido na governamentalidade da vida na rua é sempre negativo e positivo, proibitivo e produtivo. Um campo de possibilidades de ação é criado pelas tecnologias que este mobiliza, levando a que outras ações se tornem de facto impossíveis ou, pelo menos, bastante mais custosas. A restrição da cedência de moradas institucionais para receção de correspondência não tem a intenção estratégica ou subjetiva de eliminar de facto um direito (a receção de prestações públicas) a quem vive na rua - ainda que possa ter este efeito, tal como outros. $\mathrm{O}$ seu objetivo é bastante mais ambicioso e complexo. $O$ que está em causa nesta decisão-ação é a coerção à ressubjetivação tutelar usando a morada institucional como instrumento para forçar os sujeitos a associarem-se a uma localização administrativa e ontológica em troca de um rendimento minimalista.

Por esse processo, a tutela torna-se coerciva por princípio, revelando-se como uma forma de dominação. Noutras situações, a dominação está presente na relação assistencialista apenas em potência. Mas, no momento em que um sujeito precisa de assentir voluntariamente a ser governado a partir de uma instituição específica, através de um dos seus profissionais, a dominação passa da potência ao ato - mesmo que possa ser de novo remetida para o campo do obscurecimento em momentos posteriores do processo tutelar de ressubjetivação. Adicionalmente, neste mesmo momento, o direito de jure a receber uma prestação pública em caso de pobreza revela-se de facto inexistente pela sua condicionalidade absoluta e draconiana. Em troca de $178,15 €$ mensais, os sujeitos têm de se oferecer a si mesmos, têm de permitir a sua integração administrativa em bases de dados que os agregam como população, têm de aceitar um conjunto de constrangimentos, obrigatoriedades de realização de atividades e de presença em espaços-tempo concretos, caso isso lhes seja exigido, e têm de aceitar ser inseridos numa relação tutelar como parte ontologicamente inferior.

Para o funcionamento do poder na vida da rua, não basta que o sujeito aceite todas essas condições: ele tem de o fazer de um modo pelo qual se assume como sujeito, tem de o fazer de modo (superficialmente) voluntário, tem de se apresentar como sujeito da sua própria submissão, materializando este seu 
voluntarismo no momento em que assina um contrato individual de reinserção. A violência extrema da vida na rua revela-se em variadíssimos momentos e situações. Mas em nenhum outro momento ela é simbolicamente mais intensa do que aquando da exigência de submissão voluntária, do que no momento de desespero em que o sujeito é chamado a enunciar «sim, estou aqui, preciso, por isso, governem-me e digam-me como me devo governar». ${ }^{12}$

Essa violência simbólica apresenta-se ainda mais nítida quando se observam as condições quid pro quo exigidas aos sujeitos que vivem na rua para terem direito a usar a morada de uma instituição para receber correspondência. Nem em todos os casos estes sujeitos são declaradamente maltratados. Mas são-no ou não consoante o arbítrio dos profissionais assistencialistas concretos que casuisticamente decidem que condições impor a que sujeito - ainda que esta aleatoriedade opere dentro de um esquema representacional e praxiológico estandardizado, quer pela ligação fundamental de todos os corpos individuais que vivem na rua ao arquétipo de sem-abrigo anormal e anormativo, quer pelas de facto reduzidas propostas de conduta, ressubjetivação e benefícios disponíveis que, pretendendo adaptar-se a cada indivíduo, são de facto extraordinariamente semelhantes para todos os indivíduos.

Mesmo antes de aceder ao conjunto de condições draconianas pelas quais se posiciona no centro da ação de modo aparentemente voluntário e aceita ser governado sob a tutela de outrem, o sujeito tem de dar, em cada caso, provas da sua vontade em entrar seriamente nesta relação, tem de provar a sua "motivação para a mudança”. ${ }^{13}$ Casos há em que tais provas podem ser consideradas desne-

12 Este processo torna-se ainda mais violento na medida em que não é realizado com a intenção subjetiva de maltratar quem vive na rua - ainda que intencionalidades subjetivas que desejam prejudicar quem vive na rua existam dentro do dispositivo - mas, antes, pela sua conversão em "trabalho técnico", para usar uma expressão frequentemente presente nos discursos de vários profissionais assistencialistas. Ou seja, todo este processo se desenrola na forma de um ato político despolitizado e que rejeita afirmar-se como ação moral mas, enquanto techne, apresenta-se como ação adiaforética, como ação valorativamente indiferente em si mesma e que não pode ser avaliada no campo da moral (Bauman, 1991: 144 et passim, 2000: 92 et passim, 2007: 155 et passim; Bauman; Donskis, 2013: passim). Porém, sendo as possibilidades de vida de quem vive na rua diminuídas de facto nestas condições, uma techne adiaforética assente em benefícios condicionais na qual os sujeitos subordinados têm de se tornar parte ativa da sua dominação para poderem ter acesso apenas ao nível mínimo de recursos que permite a sua sobrevivência biológica não pode deixar de se revelar como imoral no sentido preciso levinasiano (Lévinas, 1988; 1991): saindo da responsabilidade pré-ontológica pelo Outro que se me apresenta como rosto, esta ação transfere a responsabilidade para os ombros do sujeito mais fraco e faz com que a parte superordinada, em vez de se tornar responsável pelo Outro, torne-se soberana face a ele.

13 Sobre a exigência continuada de provas - se assim se quiser pensar, sobre a prova como tecnologia de governo - no dispositivo assistencialista em geral, e, em particular, sobre a necessidade do sujeito provar a sua "motivação para a mudança" como condição de base da intervenção, cf. Castra (2011) e, sobretudo, Chelle (2012). 
cessárias, mas também aqui tal depende, em grande medida, da articulação da normatividade oficial do dispositivo (há etapas e documentos obrigatórios no processo) com o arbítrio do profissional do dispositivo cuja posição lhe permite considerar que provas adicionais são desnecessárias ou necessárias. Se tais provas de boa vontade do sem-abrigo concreto cuja escassez de recursos empurra para uma relação de assistência forem consideradas necessárias, ele terá de fornecê-las. Frequentemente, tal passa pela aceitação do início de um acompanhamento psiquiátrico para distúrbios mentais, alcoolismo ou toxicodependência, que opera na lógica tutelar de identificação do problema biológico-psiquiátrico (ontológico) individual, reconhecimento individual desse problema, aceitação de tratamento médico (e.g., internamento em instituição psiquiátrica ou administração de medicação) e ressubjetivação em sujeito normal e normativo.

De modo também habitual, é exigido a certos sujeitos que provem a sua motivação num registo que se localiza no cruzamento da normatividade, da norma científico-estatística e da estética. Neste caso, os indivíduos têm, sobretudo, de se mostrar dispostos e capazes de trabalhar sobre si através da sua higiene pessoal. Não é excessivo frisar a importância semiótica dessa questão para vários dos agentes do dispositivo. Os sujeitos que vivem na rua são não só percebidos como sujos; a sua sujidade é alvo de dois processos representacionais articulados. Por um lado, é generalizada à totalidade da população sem-abrigo, negando tacitamente os muitíssimos casos de indivíduos que, com um enorme esforço, mantêm uma aparência e uma higiene próxima da norma domiciliada (mais idealizada do que estatística; eles são sujos, nós somos limpos; não se aceita que a sujidade possa ser característica dos sujeitos domiciliados das classes médias e elites, apenas de quem vive na rua). Por outro lado, a falta de higiene e a estética contrastante com esta norma idealizada são remetidas para o domínio da ontologia deficiente - os sujeitos são ou não porcos devido a um conjunto de características biológico-psiquiátricas e culturais,${ }^{14}$ claramente anormais e anormativas, e não devido às circunstâncias materiais das suas vidas.

A partir desta representação englobante, certos sujeitos sem-abrigo são compelidos a deixar de ser (e não estar) sujos para provarem que estão motivados para entrar numa relação tutelar de assistência e assinar um contrato de reinserção individual junto de uma instituição assistencialista, ganhando acesso ao uso da sua morada para receber correspondência. O processo-padrão para mostrar essa motivação para largar a sujidade ontológica passa pela aceitação

14 Características culturais essas que, contudo, não são sociologicamente percebidas mas são também elas interpretadas no registo da individualização patológica. 
de um controlo exógeno de um profissional assistencialista sobre atividades como tomar banho, cortar as unhas ou cortar a barba e o cabelo.

Em grande medida, isso decorre da necessidade de corresponsabilização dos assistidos sentida por muitos profissionais assistencialistas e que se apresenta como estratégia oficial do próprio subdispositivo assistencialista. Essa exigência de corresponsabilização converte a relação de assistência numa sucessão de interações em que benefícios condicionais são cedidos numa lógica de quid pro quo segundo a qual os sujeitos sem-abrigo, não tendo mais nada para dar, têm de se dar a si mesmos, trabalhando sobre o seu íntimo problemático.

Caso correspondesse a $100 \%$ ao que é enunciado, sem desfasamento entre o discurso e a praxis, essa pretensa reciprocidade seria em si mesma desigual, exigindo bem mais em troca do que aquilo que é fornecido a quem vive na rua. Porém, na empiria, a desigualdade torna-se ainda mais fundamental, em parte, pelos desfasamentos temporais da ação. Um dos casos mais extremos de que tenho conhecimento, mas de todo não único, é o de um sujeito a quem foi exigido tomar banho regularmente numa instituição que presta (e, como se vê, em alguns casos, constrange a) esse serviço a quem não tenha outro local onde o fazer antes que lhe fosse cedida uma morada institucional e fosse iniciado o processo de requisição do Rendimento Social de Inserção. Foram necessários dois meses de deslocações regulares para tomar banho na instituição para que o profissional assistencialista que, soberanamente, decidira este regime específico de condicionalidade considerasse que, efetivamente, o sujeito estava "motivado para a mudança”, revelara-se confiável, e o processo de assistência tutelar poderia ter início. (A medicalização e a estética articulam-se: foi-lhe também exigido realizar uma desintoxicação alcoólica.) Nas palavras do profissional assistencialista em questão, "tem de ser uma contrapartida. Vamos ajudá-los, mas não vamos ter pena" (entenda-se: "pena", neste registo discursivo, seria garantir direitos incondicionais e, assim, desresponsabilizar os sujeitos que vivem na rua por viverem na rua). $\mathrm{Ou}$, nas palavras da mesma pessoa, igualmente esclarecedoras: "devemos ajudar, desculpem-me lá, é o tanas!"

Sendo o dispositivo uma articulação agonística de elementos, profissionais e instituições distintas revelam diferentes práticas. Contudo, de modo estratégico, qualquer ajuda fornecida oficialmente pelo dispositivo assenta na exigência de contrapartidas e na demonstração de disponibilidade para a realização de um trabalho sobre si tutelado. Deste modo, o princípio da assistência sob contrapartida apresenta-se como uma tecnologia de biopoder sem a qual é impossível compreender as implicações sociológicas e políticas do dispositivo de governo da vida na rua. 
O princípio da contrapartida não assenta, claro está, numa real necessidade de recebê-las por motivos materiais. Ou seja, com ou sem contrapartidas fornecidas por sujeitos sem-abrigo, o nível de vida médio dos restantes elementos de uma sociedade mantém-se inalterado. A contrapartida é um princípio político - despolitizado na forma da techne da ativação dos sujeitos pelo trabalho sobre si - que visa a ressubjetivação de quem vive na rua, tornando estes sujeitos em entidades dóceis e, eventualmente, em entidades com potencial para virem a ser produtivas. ${ }^{15}$

A contrapartida, recorrendo a uma expressão igualmente frequente nos enunciados de vários agentes do dispositivo, é um modo de "moralizar o sistema" por via da "moralização" dos assistidos. Essa moralização, definitivamente, não se processa no sentido levinasiano de responsabilização pelo Outro (Lévinas, 1988, 1991) mas, antes, no sentido de ajustamento dos sujeitos desviantes à normatividade dominante do modelo societal. Assim, trata-se de um ato de poder pelo qual os assistidos são feitos pagar um benefício minimalista com uma alteração ontológica e tornados parte ativa no processo pelo qual deixam de ser assistidos - pois a instalação na assistência apresenta-se como indicador fundamental de anormatividade e/ou anormalidade.

Dado que o dispositivo de governo da vida na rua é um mecanismo de poder com uma articulação agonística de intencionalidades subjetivas - cuja agregação resulta numa intencionalidade global não-subjetiva -, há agentes do dispositivo com posições críticas do posicionamento dominante discutido. Grande parte da crítica provém da consciência da inevitável arbitrariedade soberana inerente a todo o processo de atribuição de moradas institucionais e, em geral, ao processo de assistência condicional. Há profissionais assistencialistas que consideram que a cedência de uma morada institucional para receção de correspondência "não é um favor que lhes fazemos [aos sujeitos sem-abrigo]" pelo que tem de operar num regime de responsabilidade política do dispositivo e dos seus profissionais e não num regime de aleatoriedade soberana. Porém, esta é uma posição claramente minoritária dentro do dispositivo, sendo os enunciados emitidos neste registo (e quem os enuncia) representados de forma negativa pelos restantes agentes.

Para diversos profissionais assistencialistas, $\mathrm{o}$ argumento que serve para rebater o enunciado crítico é o da desnecessidade da cedência institucional de

15 Num registo bem diferente do que vigorava no Século XIX, quando a produtividade dos corpos tinha uma relação bastante mais direta com a sua ressubjetivação (Foucault, 2012a). Hoje, com taxas de desemprego estrutural de dois dígitos, a ressubjetivação como sujeito dócil e produtivo não implica de forma direta a possibilidade de ocupação de uma posição reticular que permita efetivar essa nova subjetivação. 
moradas para recebimento de correspondência (incluindo os cheques com que é pago mensalmente o Rendimento Social de Inserção). A partir deste último - e mais frequente - posicionamento, em última análise, os sem-abrigo poderiam arrendar um apartado ${ }^{16}$ nos $\mathrm{CTT}^{17}$ para receberem correspondência, não havendo necessidade de mediação institucional. Deste modo, só com a aceitação do trabalho sobre si esta cedência de morada faz sentido. A proveniência do dinheiro para arrendar um tal apartado não entra no argumento. Certamente, ele proviria do próprio Rendimento Social de Inserção para cuja receção o apartado seria arrendado, levando a que, dada exiguidade do montante desta prestação pública, em rigor, o apartado fosse arrendado para a receber e, em parte, esta fosse recebida para pagar o arrendamento do apartado.

A partir desta posição dominante, a cedência de moradas institucionais não é uma responsabilidade política, moral ou sequer técnica, uma vez que há alternativas. Porém, dada a escassez de recursos de quem vive na rua, a alternativa que está em causa é menos uma escolha de facto do que uma fantasia-de-escolha. ${ }^{18} \mathrm{O}$ processo de cedência de moradas institucionais a quem pernoita literalmente na rua revela-se como uma forma de tornar estes sujeitos dependentes das instituições da parte oficialmente assistencialista do dispositivo de governo da vida na rua, pois esses sujeitos só acedem à possibilidade de nelas receberem correspondência submetendo-se às condições impostas exogenamente de modo não negociável. Assim, a operação desta tecnologia reforça a dependência factual dos sujeitos - mesmo operando dentro de um registo que, pelo menos ao nível dos enunciados, visa a sua autonomização (através da sua normalização e normativização). Ou seja, tornando os sujeitos dependentes das instituições assistencialistas - via instituição concreta, via profissional assistencialista

16 Termo usado em Portugal para "caixa postal".

17 Correios e Telecomunicações de Portugal. A sigla CTT provém da designação anterior, Correios, Telégrafos e Telefones.

18 Em 2015, o preço anual de arrendamento de um apartado nos CTT era de 61.50€. Dado que o Rendimento Social de Inserção tinha um valor máximo de $178.15 €$ mensais, um apartado representava cerca de $2.88 \%$ deste montante, aproximadamente o mesmo que custa uma refeição ou um produto elementar de higiene pessoal. Face à escassez brutal de recursos de quem vive na rua, afirmar exogenamente que este valor poderia ser usado para o arrendamento de um apartado é um enunciado em si mesmo violento. Para mais, pressupõe que, para que uma tal alocação de recursos não tivesse como custo de oportunidade uma refeição que se deixaria de consumir, os sem-abrigo tenham, como princípio-exigência de governo, de se alimentar em exclusivo do que lhes é disponibilizado como caridade institucional. Do mesmo modo, ao levar a que se prescinda da aquisição de um produto elementar de higiene pessoal, uma tal alocação de recursos facilmente resultaria numa governamentalidade da vida na rua na qual os sem-abrigo seriam institucionalmente forçados a apresentar precisamente a higiene e a estética normativamente desprezadas pelo próprio dispositivo e que são em si mesmas interpretadas como razões para os inserir numa relação tutelar na qual devem ser ressubjetivados. 
concreto -, é reforçada a expulsão do sujeito do campo da normatividade dominante e a sua entrada no âmbito da arbitrariedade soberana com que se decide se ele tem ou não direito a uma morada oficial, logo, tem ou não direito a uma prestação pública, logo tem ou não direito a um direito, logo, tem ou não "direito a ter direitos" (Arendt, 2010: 353-401).

Os paradoxos deste processo são inegáveis. Partindo do pressuposto acriticamente aceite de que os sem-abrigo são anormais e anormativos, a assistência condicional tem como propósito explícito autonomizar esses sujeitos. Nos termos do dispositivo, esta autonomização implica a realização de um trabalho sobre si através do qual os sujeitos ultrapassam a anormalidade e a anormatividade que os constrange a partir do seu íntimo. Mas, para desenvolver este processo de autonomização, os sem-abrigo têm de ser firmemente inseridos numa situação de heteronomia no seio de uma relação tutelar na qual estão sujeitos às decisões arbitrárias da parte superordinada. Deste modo, por definição, esta forma de autonomização não autonomiza, pois opera de uma forma que reforça a submissão sociopolítica de quem vive na rua e a sua dependência (inferioridade) em relação às instituições e profissionais assistencialistas (Chelle, 2012; Duvoux, 2012; Franssen, 2003; 2006; Le Goff, 2006).

Ao longo de todo este processo, é reforçada a negação de um direito específico - e, no limite, a negação do direito a ter direitos. Por definição, quem vive na rua vê vedado o acesso à habitação como realidade praxiológica - com as suas dimensões jurídica, arquitetônica, emocional e sociológica. Mas, pelo processo descrito, de modo acrescido, é igualmente negado a estes sujeitos o direito à morada - aqui já não como realidade sociológico-jurídica mas tão somente como realidade administrativa. Mesmo a abstração que é a morada torna-se incompatível com a vida na rua.

\section{Conclusão}

Como mostra a cedência de moradas institucionais, o dispositivo de governo da vida na rua opera de modo privilegiado através de intervenções individualizadas e individualizantes, dirigidas a cada um dos sujeitos sem-abrigo, percebidos como fundamentalmente insuficientes. Num registo de invisibilização e/ou naturalização estrutural, esta insuficiência de quem vive na rua é percebida como causa exclusiva para que os sujeitos sejam sem-abrigo. Por alargamento desta lógica através do somatório de indivíduos insuficientes, toda a população sem-abrigo passa a ser interpretada como inerentemente patológica, anormal e/ou anormativa. Deste modo, no dispositivo de governo da vida na 
rua, qualquer eventual solução para que cada indivíduo específico deixe de ser sem-abrigo tem de passar pela sua transformação fundamental. O sujeito tem de deixar de ser quem e o que é.

Porém, sendo este sujeito ontologicamente insuficiente, por si mesmo, ele é percebido como incapaz de realizar este processo de ressubjetivação. Assim sendo, o dispositivo procura inseri-lo numa relação tutelar com profissionais assistencialistas no âmbito da qual esta transformação pode ter origem. Contudo, a relação tutelar tende a ser transformada numa interação de dominação na qual a ressubjetivação de facto estimulada se apresenta como submissão dos sem-abrigo, que deverão aceitar os constrangimentos brutais que a vida na rua lhes impõe.

É esta submissão que o dispositivo procura gerar através do uso particular que dá à cedência de moradas institucionais. Em si mesma, a forma como esta tecnologia é mobilizada é constrangedora. Ela força - e pretende forçar - a introdução de cada sem-abrigo necessitado de uma morada onde possa receber correspondência numa relação de profunda dependência face às instituições e profissionais assistencialistas. Ao nível do discurso explícito, esta relação visa criar condições interiores no sujeito para que ele deixe de ser dependente. Porém, na praxis, esta relação solidifica-o numa posição de dependência-como-submissão e a operação factual de tecnologias como a cedência de moradas institucionais cria bloqueios significativos a qualquer saída desta situação.

No limite, a cedência de moradas institucionais expressa um posicionamento sociopolítico mais abrangente do dispositivo de governo da vida na rua face a quem vive na rua. E, na medida em que este dispositivo age dentro de um modelo societal específico, para cuja legitimação e reprodução contribui, a cedência de moradas institucionais manifesta o próprio posicionamento dominante deste modelo societal face aos sem-abrigo. Representados de modo negativo e apenas negativo, compreendidos como detendo no seu íntimo individual (por vontade ou incapacidade) os motivos para a sua posição social desqualificada, eles são feitos sair do regime do "direito a ter direitos" e localizados num campo em que o seu tratamento será bom ou mau segundo a avaliação exógena que outrem faz da sua conduta. Contendo sempre um grau de arbítrio, esta decisão determina o acesso a recursos ou a sua negação, condicionando as possibilidades de vida dos sem-abrigo. Não pretendendo o fim da sua vida biológi$\mathrm{ca}$ - que é precisamente aquilo que o dispositivo, e logo, o modelo societal em que este existe, considera como merecedor de preservação -, a ação estratégica do dispositivo através de tecnologias como a cedência de moradas institucionais impede o desenvolvimento de formas de vida para além da mera biologia, 
negando aos sem-abrigo os mais elementares direitos que são reconhecidos aos sujeitos domiciliados das classes médias e elites cujas vidas são politicamente qualificadas de modo positivo.

\section{Referências}

AGAMBEN, Giorgio. O poder soberano e a vida nua. Homo sacer. Lisboa, Presença, 1998 (1995).

. O que é um dispositivo? In: idem, O que é o contemporâneo? e outros ensaios. Chapecó, Argos, 2009, pp. 25-51. . Estado de excepção. Lisboa, Edições 70, 2010 (2003).

ARENDT, Hannah. A condição humana. Lisboa, Relógio D’Água, 2001 ( 1958). . As origens do totalitarismo. Alfragide, Dom Quixote, 2010 (1951).

ARNOLD, Kathleen R. Homelessness, Citizenship, and Identity. The Uncanniness of Late Modernity. New York, State University Press of New York, 2004.

BAUMAN, Zygmunt. The Social Manipulation of Morality. Moralizing Actors, Adiaphorizing Action. Theory, Culture \& Society, n. 8, 1991, pp. 137-151.

. Ethics of Individuals. Canadian Journal of Sociology/Cahiers canadiens de sociologie, v. 25, n. 1, 2000, pp. 83-96.

. A vida fragmentada. Ensaios sobre a Moral pós-moderna. Lisboa, Relógio D’Água, 2007 (1995).

BAUMAN, Zygmunt; DONSKIS, Leonidas. Moral Blindness. The Loss of Sensitivity in Liquid Modernity. Cambridge/Malden, Polity, 2013.

BINKLEY, Sam. Psychological Life as Enterprise. Social practice and the government of neo-liberal interiority. History of the Human Sciences, v. 24, n. 3, 2011, pp. 83-102.

CASTRA, Dennis. L'insertion professionnelle des publics précaires. Paris, PUF, 2011 (2003). CHELLE, Élisa. Gouverner les pauvres. Politiques sociales et administration du mérite. Rennes, Presses Universitaires de Rennes, 2012.

CONRAD, Peter. Medicalization and Social Control. Annual Review of Sociology, n. 18, 1992, pp. 209-232.

. The Medicalization of Society. On the Transformation of Human Conditions into Treatable Disorders. Baltimore, The John Hopkins University Press, 2007.

CONRAD, Peter; SCHNEIDER, Joseph W. Deviance and Medicalization. From Badness to Sickness. Expanded Edition, with a new afterword by th authors. Philadelphia, Temple University Press, 1992 (1980).

DELEUZE, Gilles. What is a dispositif? In: T. J. Armstrong (org.), Michel Foucault. Philosopher. New York, Routledge, 1992, pp. 159-168 (1989).

DUVOUX, Nicolas. L'autonomie des assistés. Sociologie des politiques d'insertion. Paris, PUF, 2012 (2009). 
ELIAS, Norbert. Envolvimento e distanciamento. Estudos sobre sociologia do conhecimento. Lisboa, Dom Quixote, 1997 (1990). . A sociedade dos indivíduos. Lisboa, Dom Quixote, 2004 (1987). . Introdução à sociologia. Lisboa, Edições 70, 2005 (1970).

. O processo civilizacional. Investigações sociogenéticas e psicogenéticas. Lisboa, Dom Quixote, 2006 (1939).

ESPOSITO, Roberto. Bios. Biopolítica e filosofia. Lisboa, Edições 70, 2010 (2004). . Immunitas. The Protection and Negation of Life. Cambridge/Malden, Polity, 2011 (2002).

FELDMAN, Leonard C. Citizens Without Shelter. Homelessness, Democracy and Political Exclusion. Ithaca/London, Cornell University Press, 2006 (2004).

FOUCAULT, Michel. About the Concept of the "Dangerous Individual. In 19th-Century Legal Psychiatry”. International Journal of Law and Psychiatry, n. 1, 1978, pp. 1-18. . "The Politics of Health in the Eighteenth Century. In: C. Gordon (org.) e Michel Foucault, Power/Knowledge. Selected Interviews and Other Writings, 1972-1977. New York, Pantheon, 1980a, pp. 166-182 (1976).

. The Confession of the Flesh. In: C. Gordon (org.) e Michel Foucault, Power/ Knowledge. Selected Interviews and Other Writings, 1972-1977. New York, Pantheon Books, 198ob, pp. 194-228 (1977).

. The Subject and Power. In: H. L. Dreyfus e P. Rabinow (org.), Michel Foucault.

Beyond Structuralism and Hermeneutics. Chicago, Chicago University Press, 1983, pp. 208-226 (1982).

. História da sexualidade - I. A vontade de saber. Lisboa, Edições 70, 1994 (1976). . Les anormaux. Cours au Collège de France, 1974-1975. Paris, EHESS/Gallimard/ Seuil, 1999.

. «É preciso defender a sociedade». Curso no Collège de France (1975-1976).

Lisboa, Livros do Brasil, 2006 (1997).

. Security, Territory, Population. Lectures at the Collège de France, 1977-1978.

Basingstoke/New York, Palgrave Macmillan, 2009 (2004). . Nascimento da biopolítica. Lisboa, Edições 70, 2010 (2004). . Surveiller et punir. Naissance de la prison. Paris, Gallimad, 2012a (1975).

. Du gouvernement des vivants. Cours au Collège de France, 1979-1980. Paris, EHESS/Gallimard/Seuil, 2012b.

FRANSSEN, Abraham. Le sujet au coeur de la nouvelle question sociale. La Revue Nouvelle, n. 12, 2003, pp.10-51.

. L'État Social actif et la nouvelle fabrique du sujet. In: I. Astier e N. Duvoux (orgs.), La société biographique. Une injoction à vivre dignement. Paris, L'Harmattan, 2006, pp. 75-104. 
GEREMEK, Bronislaw. La potence ou la pitié. L'Europe et les pauvres du Moyen Âge à nos jours. Paris, Gallimard, 2010 ( 1978).

GOWAN, Teresa. Hobos, Hustlers and Backsliders. Homeless in San Francisco. Minneapolis/London, University of Minnesota Press, 2010.

HOPPER, Kim. Reckoning with Homelessness. Ithaca/London, Cornell University Press, 2003.

LAW, John. Power, Discretion and Strategy. In: (org.), A Sociology of Monsters. Essays on Power, Technology and Domination. London/New York, Routledge, 1991, pp. 165-191.

LE GOFF, Frédérique. Lorsque les stratégies d'empowerment épousent les trajectoires. Laide à l'emploi dans des organismes communautaires au Québec. In: I. Astier e N. Duvoux (orgs.), La société biographique. Une injoction à vivre dignement. Paris, L'Harmattan, 2006, pp. 139-172.

LÉVINAS, Emmanuel. Totalidade e infinito. Lisboa, Edições 70, 1988 (1961). Otherwise than Being or Beyond Essence. Dordrecht, Kluwer Academic Publishers, 1991 (1974).

LOVELL, Anne M. Classification and Its Risks. How Psychiatric Status Contributes to Homelessness Policy. New England Journal of Public Policy, v. 8, n. 1, 1992, pp. 247-263.

LYON-CALLO, Vincent. Inequality, Poverty and Neoliberal Governance. Toronto, University of Toronto Press, 2008 (2004).

MATHIEU, Arline. The Medicalization of Homelessness and the Theater of Repression. Medical Anthropology Quarterly, v. 7, n. 2, 1993, pp. 170-184.

RAFFNSØE, Sverre; GUDMAND-HØYER, Marius; THANING, Morten S. "What is a dispositive?" Foucault's historical mappings of the networks of social reality. Open Archive, 2014. Disponível em: <http://openarchive.cbs.dk/bitstream/handle/10398/9077/Raffnsoe.pdf? sequence=1>. Acesso em: 04 abr. 2019.

SCHMITT, Carl. Political Theology. Four Chapters on the Concept of Sovereignty. Chicago/London, University of Chicago Press, 2005 (1922).

STRONG, Tracy B. Foreword. The Sovereign and the Exception: Carl Schmitt, Politics, Theology, and Leadership. In: C. Schmitt, Political Theology. Four Chapters on the Concept of Sovereignty. Chicago/London, University of Chicago Press, 2005, pp. 7-35. WASSERMAN, Jason Adam; CLAIR, Jeffrey Michael. At Home on the Street. People, Poverty \& a Hidden Culture of Homelessness. Boulder/London, Lynne Rienner Publishers, 2010.

Recebido em 13/02/2017

Aprovado em 17/10/2018 


\section{Como citar este artigo:}

ALDEIA, João. A dificuldade de morar. Exercícios de poder no fenômeno dos sem-abrigo. Contemporânea - Revista de Sociologia da UFSCar, v. 9, n. 1, jan.- jun. 2019, pp. 145-171. 